mechanisms: (1) granulomatous infiltration of the larynx with normal vocal cord motility, occurring in $5 \%$ of cases 6 -a serious lesion that might result in stridor and respiratory distress; (2) sarcoid cranial polyneuropathy with dysphonia and dysphagia, resulting from sarcoid affecting the vagus nerve-a condition invariably associated with other neurological lesions, particularly facial nerve palsy ${ }^{7}$; (3) compression of the left recurrent laryngeal nerve,${ }^{45}$ produced by a sarcoid lymph node as it hooks around the arch of the aorta, as in carcinoma of the bronchus.

To our knowledge, compression of the left recurrent laryngeal nerve by sarcoid nodes has been described on only two previous occasions. ${ }^{45}$ Other benign conditions causing mediastinal lymphadenopathy and compression of the left recurrent laryngeal nerve- namely, tuberculosis ${ }^{12}$ and pneumoconiosis ${ }^{3}-$ have been described rarely.

1 Fowler RW, Hetzel MR. Tuberculous mediastinal lymphadenopathy can cause left vocal cord paralysis. $\mathrm{Br}$ Med 1983;286:1562.

2 Hamilton JRL, Varghese G, Shepperd HWH, Stevenson HM. Tuberculous left vocal cord palsy: a timely reminder. $J$ Laryngol Otol 1986;100:837-8.

3 Sherani TM, Angelini GD, Passani SP, Butchart EG. Vocal cord paralysis associated with coalworkers' pneumoconiosis and progressive massive fibrosis. Thorax 1984; 39:683-4.

4 Swinburn CR, Pozniak AL, Davies DG, Treasure T, Johnson NM. Left recurrent laryngeal nerve palsy as the presenting feature of sarcoidosis. Sarcoidosis 1986;31: 67-8.

5 Chijimatsu Y, Tajima J, Washizaki M, Homma H. Hoarseness as an initial manifestation of sarcoidosis. Chest 1980;78:779-81.

6 Neville E. Upper respiratory tract sarcoidosis. Semin Respir Med 1986;8:52-8.

7 Matthews WB. Sarcoid neuropathy. In: Dyck PJ, Thomas PK, Lambert EH, Bunce R, eds. Peripheral neuropathy. Vol 2. 2nd ed. Philadelphia: Saunders, 1984:2018-20.

\section{Constrictive pericarditis caused by primary liposarcoma}

\author{
R J Lionarons, J van Baarlen, \\ J F Hitchcock
}

\section{Department of}

\section{Cardiology}

R J Lionarons

Department of

Pathology

$\mathrm{J}$ van Baarlen

Department of

Cardiothoracic

Surgery

J F Hitchcock

University Hospital,

Utrecht,

The Netherlands

Address for reprint requests: DrR J Lionarons,

Department of Cardiology,

Militair Hospitaal

"Dr A Mathijsen",

J Haydnlaan 2, $3533 \mathrm{AE}$

Utrecht, The Netherlands.

Accepted 18 January 1990

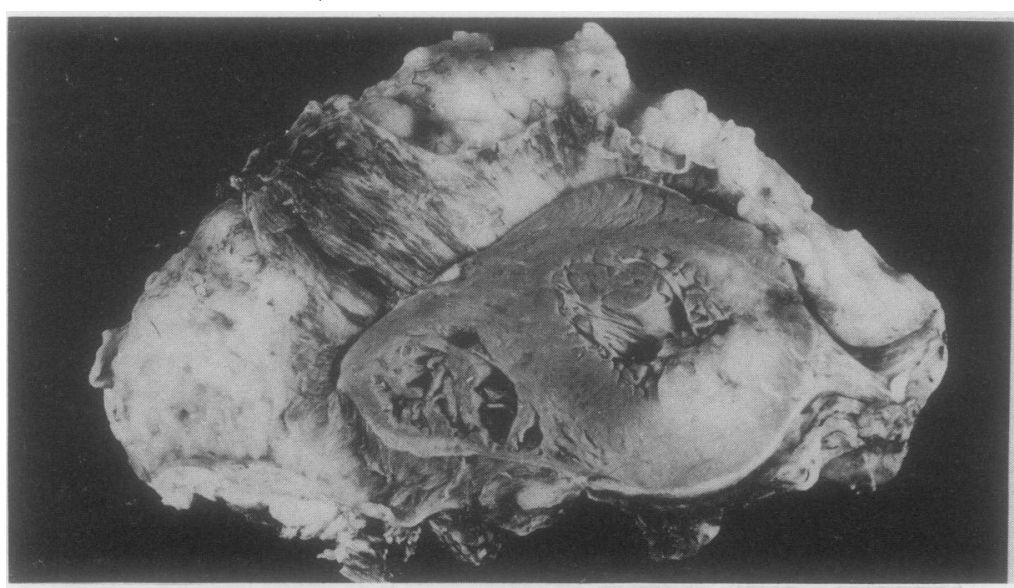

Figure 1 Transverse section of the heart at the level of both ventricles showing the tumour extending from the parietal to the visceral pericardium. At the lower right side the tumour has infiltrated the left ventricular wall. constrictive pericarditis caused by primary liposarcoma in a 30 year old man.

\section{Case report}

A 30 year old white man presented with a two month history of progressive dyspnoea on exertion, left sided chest pain that radiated to the left shoulder, general malaise, weight loss, anorexia, night sweats, fever, and pronounced peripheral oedema. He was transferred to us from a small regional hospital with a diagnosis of suspected right sided endocarditis. On examination the patient was ill with severe dyspnoea at rest. His blood pressure was 120/ $85 \mathrm{~mm} \mathrm{Hg}$ with pulsus paradoxus of about 30 $\mathrm{mm} \mathrm{Hg}$. The heart rate was regular at 116 beats $/ \mathrm{min}$ and the temperature was $37.8^{\circ} \mathrm{C}$. Venous pressure was visible at the angle of the jaw and his abdomen was swollen and tender with considerable hepatomegaly and ascites. Severe pitting oedema of the legs extended to the sacrum. There were broadened precordial pulsations, an apex beat palpated outside the midclavicular line, and very faint heart sounds, with a grade $2 / 6$ systolic murmur along the right sternal border and a pericardial friction rub near the apex.

A chest radiograph showed enlargement of the heart, with irregular margins extending to the left thoracic wall, and a pleural effusion. An electrocardiogram was low voltage and showed non-specific $T$ wave changes. Echocardiography showed a huge, irregular tumour mass surrounding the greater part of both ventricles and infiltrating the apex of the left ventricle. There was considerable limitation of diastolic filling. Computed tomography showed no extension outside the pericardium. An anterolateral thoracotomy was performed for diagnostic purposes and to decompress the myocardium. The heart was encircled by a large, richly vascular, mucoid, multilobular, green-yellow, glistening mass, encapsulated by the pericardium and attached to the apex of the left ventricle. 
Figure 2 Tumour cells with large and irregular hyperchromatic nuclei. The cytoplasm was slightly eosinophilic. The large number of fat containing vacuoles of varying size give the cells a grape like appearance.

(Haematoxylin and eosin; (a) $\times 160,(b) \times 640$.)

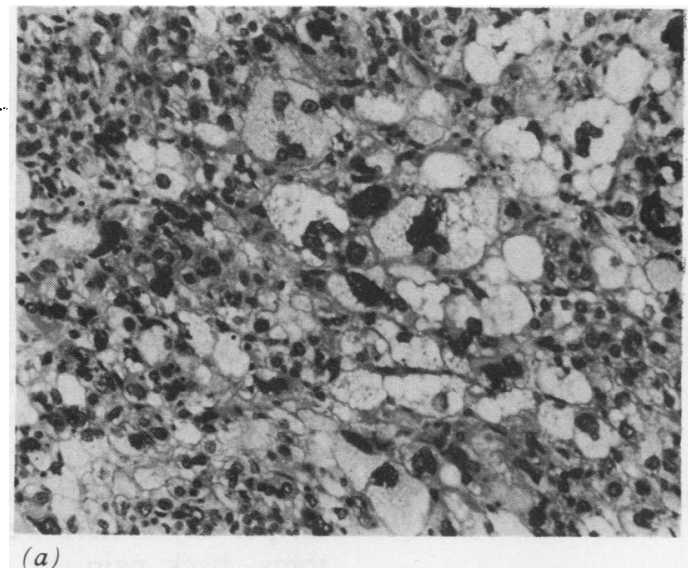

Frozen section examination of the tumour showed liposarcoma. Resection was impossible and the patient was allowed to die under anaesthesia according to his explicit wish before surgery if the tumour was malignant and inoperable. At necropsy the heart was encased by irregular green and yellow fatty and mucoid tissue, $25 \mathrm{~cm}$ in diameter, seen to contain small quantities of mucoid fluid when sectioned. The heart and tumour weighed $2750 \mathrm{~g}$. The tumour was continuous with the visceral and parietal pericardium, infiltrating the apical part of the anterior and lateral left ventricle (fig 1). No metastases were identified. Light microscopic examination showed irregularly shaped cells, with large pleomorphic nuclei and slightly eosinophilic cytoplasm often containing grape like organised vacuoles, set in a stroma (fig 2 ). The vacuoles in many of the tumour cells stained positively with oil red $\mathrm{O}$, confirming that they were fat (lipoblasts). Electron microscopic examination confirmed the diagnosis of pleomorphic liposarcoma.

\section{Discussion}

Liposarcomas occur principally in the retroperitoneal space and lower extremities and less commonly in the abdomen, buttock, vulva, neck, ${ }^{1}$ and mediastinum. ${ }^{2}$ Primary liposarcoma of the heart has been reported

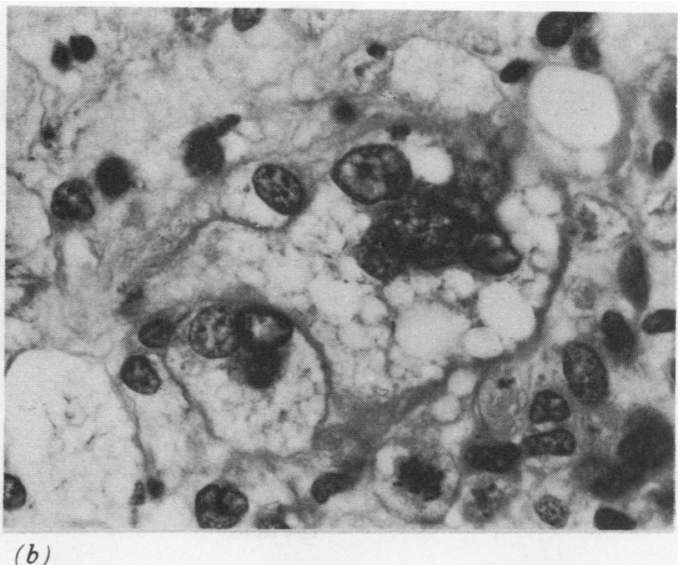

only twice-arising within the right ventricle ${ }^{3}$ and the right atrium. ${ }^{4}$ This is the first case report of a primary liposarcoma of the pericardium. Lagrange et al described one case of cardiac metastases from a myxoid liposarcoma and referred to four other cases. ${ }^{5}$

Primary malignancies of the pericardium are rare and include mesothelioma, fibrosarcoma, angiosarcoma, and malignant teratoma. This case shows features similar to those of other primary malignant pericardial tumours, with a tendency to encase the pericardium, obliterate the pericardial space, and cause constriction of the heart. ${ }^{6}$ Of the diagnostic procedures we performed, echocardiography and computed tomography appeared to be the most useful. Malignant pericardial tumours typically present late, as in this case, which makes successful surgical removal unlikely.

1 Brasfield RD, Das Gupta TK. Liposarcoma. Cancer 1970;20:3-27.

2 Schweitzer DL, Aguam AS. Primary liposarcoma of the mediastinum. J Thorac Cardiovasc Surg 1977;74:83-97.

3 Mavroudis C, Way LW, Lipton M, Gertz EW, Ellis RJ. Diagnosis and operative treatment of intracavitary liposarcoma of the right ventricle. $J$ Thorac Cardiovasc Surg 1981;81:137-40.

4 Blake S, Kealy WJ, O'Loughlin S. Liposarcoma of the right atrium. J Ir Med Ass 1972;65:106-8.

5 Lagrange J-L, Despins P, Spielman M, et al. Cardiac agrange J-L, Despins P, Spielman $\mathrm{M}$, et al. Cardiac
metastases. Case report on an isolated cardiac metastasis of metastases. Case report on an isolated cardiac me

6 Kralstein J, Frishman W. Malignant pericardial diseases: diagnosis and treatment. Am Heart J1987;113:785-90. 